\title{
The Power to Choose or Power to Lose? Networked Individualism and the Usage of Social Media
}

\author{
Tadej Praprotnik \\ University of Primorska, Faculty of Humanities, Slovenia \\ tadej.praprotnik@fhs.upr.si
}

\begin{abstract}
The aim of the paper is to highlight some current characteristics of social media usage among individuals and to question the modern power of individuals to personalise their experience with media information. Social media are modern communication channels and a framework for communicating and establishing relationships. The paper therefore presents some global trends characteristic for modern society. The starting point is so-called networked individualism, typical for modern culture with an individual at the centre and lots of connections around him. Our society is a network society, so networking is one of the basic organisational principles. The paper problematises communication practices within social network sites and presents some explanations. The paper introduces a comparison between early text-based (anonymous) on-line communication (chat rooms and discussion forums), which were more topic oriented, and current networking and communication via social network sites, which are more person oriented. The major shift is from communication toward networking. Networking presupposes lots of networked and connected people, which has an influence on communication practices; because it is difficult to maintain deep and content-rich communication with lots of individuals, the phatic function of communication is prevailing. Within social network sites different types of information are exchanged. The motivation to be nice and conflict-avoidant influence what kind of information and what kind of communication we are looking for. The prevalence of "light" information is just one characteristic. The actual usage of social media also promotes the cultural logic of branding the self, which causes the modification of values. Nowadays the visibility and attention have become the driving force of most social media users.
\end{abstract}

The paper also highlights and discusses potential obstacles regarding modern usage of social media. The well-informed citizen is a precondition for robust democracy. The power of the citizen to choose what to consume and what kind of information best suits them is a welcome novelty but it also might confront us with problematic scenarios. That is to say social media optimism is based mainly on the technodeterministic viewpoint of empowering technology. The power to choose also means the power not to choose or to avoid. Individuals have lots of ways to manage information and to filter information. But this is a double-edged sword, because now individuals have a much greater opportunity to skip or to ignore lots of information usually distributed by traditional media. The diversity of the communication channels and (media) information has the potential to make us less diverse. In terms of the power to choose and control information, the empowered citizen is therefore questioned in order to stress the importance of media literacy for the future development of societies. Digital technologies can be a very powerful tool, but nevertheless they are just technologies - their usage is a reflection of the individual. The paper stresses the potential danger when individuals build their knowledge mostly or solely upon information they choose themselves, or upon their Facebook friends. As we develop digital technologies, the digital divide is not vanishing. On the contrary; the gap between well- and poorly informed citizens is becoming even deeper.

Keywords: digital technologies, social media, networked individualism, communication, identity 


\section{Introduction: technologies and societies in interaction}

"The technology cannot save us from ourselves; it can only reflect all too candidly who we are" (Barber 2002).

The aim of the paper is to question some common and popular predictions about how the internet and especially social media would change society and the individual in particular, who is nowadays at the centre of society. Namely, we are living in an individualistic society. The optimism of so-called empowered and well-informed citizens also has its roots in the developing technology. Individuals are fully equipped with smartphones and other communication devices. Besides this, we have been transformed from passive consumers or viewers into so-called produsers (prosumers), who take an active part in consuming as well as producing (media) information. Interactivity and proactivity are especially highly valued values in modern society. But are we really moving toward greater interactivity in terms of media use, in terms of exploring ourselves, and in terms of creative networking among people?

Modern times are highly controversial in many aspects. The media and popular discourses are full of optimistic prophecies concerning the individual. But do we really meet that empowered individual when we look at actual communication practices? What kind of power we are talking about? So, let us ask ourselves: are we really becoming a fully responsible society, are individuals fully equipped with the relevant information in order to discuss and bring relevant solutions concerning future society, and do individuals fully explore themselves in order to understand themselves? Are individuals really fully in command? What kind of command? What kind of power has been put to individuals? Is this popular discourse about strong individuals only an ideological mechanism trying to convince individuals about their power?

It is quite usual in popular media discourse to picture individuals who are fully confident, strong, who know what they are living for. It is a basic frame of modern discourse: individuals and their strengths, their capabilities and opportunities. Nowadays, the power is put fully into the hands of individuals. The presentation of technology as an empowering force is also in line with these popular representations of the individual. Technology is quite commonly represented as a solution for all the troubles or obstacles which individuals or society come across. In the last decade, this empowering force inscribed to technology has become even bigger. What happened? One of the major changes is the growth of social media and activities performed through social media: networking, collaboration, sharing, etc. Social media are not information channels, they are mostly communication channels. They are vehicles for social interaction. At the centre of these networks are individuals.

\section{Social media as a transforming force?}

It is well known that modern societies are in a constant phase of transformation. The reasons are diverse; the use of technology is one of the major forces. Uwe Hasebrink and Andreas Hepp acknowledge some current trends that characterise the change of the present media environment. Within these trends they list "differentiation of a vast number of technologically based media of communication, second, an increasing connectivity of and through these media, which offers the possibility to individually and collectively 'link' across space and time, third, a rising omnipresence of media that creates the possibility to connect permanently and everywhere, fourth, a rapid pace of innovation, the emergence of 'new' media and services in ever-shorter periods of time, and fifth, a datafication, which is the representation of social life in computerized data via media devices and their underlying software and infrastructure"(Hasebrink, Heep 2018, 19). The enumerated trends are closely linked with one another, and altogether they are characteristic of the current changes in our media environment. They are manifestations of deep mediatisation (Hasebrink, Heep 2018, 19). On the other hand, it is quite typical 
for our time to understand technologies as a major driving force of societies, either as 'negative' or 'positive' vehicles producing some effects. This kind of techno-pessimism and techno-optimism is especially typical when talking about social media. Both assume that the Internet is the solution to society's problems and that it can perfect society and get rid of the existence of problems. Christian Fuchs points out that the "internet and social media act as arena of ideological projections of fears and hopes that are associated with moral panics-some argue that they are dangerous spaces that are used by terrorists, rioters, vandals and criminals and therefore needs to be policed with the help of Internet surveillance, whereas others argue that the Internet is a new space of political hope that is at the heart of demonstrations, rebellions, protests and revolutions that struggle for more democracy. What both discourses share is a strong belief in the power of technology independently of society, they mistake societal phenomena (crime, terror, crises, political transformation) to be caused and controllable by technology" (Fuchs 2015, 18-20). Both versions are techno-deterministic. As Fuchs continues: "societal phenomena merely express themselves in communicative and technological spaces; technologies do not cause them. Technological determinism inscribes power into technology; it reduces power to a technologically manageable phenomenon and therefore neglects the interaction of technology and society" (Fuchs 2015, 20). Technology gives us opportunities and affordances; technology doesn't change us, or as Paul di Maggio reformulates this conclusion in a similar manner: "the Internet will not make the politically apathetic vote, or the atheist go to church" (DiMaggio 2014). The same is true of various modern revolutions: "The Eqyptian revolution was a revolution against capitalism's multidimensional injustices, in which social media were used as a tool of information and organization, but were not the cause of the revolution" (Fuchs 2015, 21). Potentials and motivations are part of a society, they are not the effects of technology. "Which potentials are realized is based on how society, interests, power structures, and struggles shape the design and usage of technology in multiple ways that are also potentially contradictory" (Fuchs 2015, 20). We have already been faced with several disappointments regarding the transformative potentials of the Internet, which were inspired by technooptimism. James Curran, Natalie Fenton and Des Freedman in their book Misunderstanding the Internet acknowledge in the same spirit that a decontextualised focus on the technology of the internet leads to misperceiving its impact. They enumerate different technology-centred predictions about how the Internet would change society, and then present what actually happened. "The internet did not promote global understanding in the way that had been anticipated because the internet came to reflect the inequalities, linguistic division, conflicting values and interests of the real world. The internet did not spread and rejuvenate democracy in the way that had been promised, partly because authoritarian regimes usually found ways of controlling the internet, but also because alienation from the political process limited the internet's emancipatory potential. The internet did not transform the economy, partly because the underlying dynamics of unequal competition that make for corporate concentration remained unchanged. Lastly, the internet did not inaugurate a renaissance of journalism; on the contrary, it enabled leading news brands to extend their ascendancy across technologies, while inducing a decline of quality not offset, so far, by new forms of journalism. All four predictions were wrong because they inferred the impact of the internet from its technology and failed to grasp that the internet's influence is filtered through the structures and processes of society" (Curran, Fenton, Freedman 2012, 179).

\section{The usage of social media as a double-edged sword; opportunities and actual realisations from the point of view of the individual}

Social media are not important only for societies as a whole. They have 'revolutionised' the everyday life of individuals, too. Social media give individuals opportunities for different organisation of life, enabling them a vast field of communication and exploration of potential lifestyle possibilities. The basic frame of social media is networking, which has become an important resource for establishing connections, to explore new lifestyles, and to develop skills needed for successful life planning. Networking is our main organisational principle. We are constantly connected to one another. Manuel Castells briefly summarises the basic frames of the modern network society in the following manner: 
"A primary dimension of these changes is what has been labelled the rise of the Me-centered society, or, in sociological terms, the process of individuation, the decline of community understood in terms of space, work, family, and ascription in general. This is not the end of community, and not the end of place-based interaction, but there is a shift toward the reconstruction of social relationships, including strong cultural and personal ties that could be considered a form of community, on the basis of individual interests, values, and projects” (Castells 2014, 136-137).

Within social media networking a great deal of power is put to ordinary people. They are in the centre of networks. They form their networks of affiliations and personal relationships within already established offline social networks; they also find other people to whom they are connect, and they select information they regard as important for them. They have the power to present themselves on social media platforms (such as Facebook or Instagram) as they want. It seems like we are living in a world perfectly fitted to ourselves. In the rest of the paper we would like to question some current practices within social media and focus our attention on the power of the individual.

At the beginning we would like to articulate our main objective and present questions outlining the paper: What is an intriguing moment manifested on social media ${ }^{1}$ ? What types of motivations are put to the front within social media? What types of communication acts are typical for social media? Do we enlarge our networks since we have an effective tool to go beyond our well-known social territory? Do we explore ourselves by using these networks? Have we broadened our symbolic and real world? The answers are not straightforward.

\section{Social media as an extension of everyday life?}

When considering the impact of social media upon individuals we have to rethink what the basic motivations are to participate within social media? Are they effective means for more successful circulation of ideas? For widening the possibilities for critical thinking? What type of progress do we have in mind when we celebrate social media? Isn't social media just a tool we have to accept and live with? Certainly, each technology has a certain kind of influence upon society but the extent of its influence is a result of the values and motivations of society.

The technological opportunities are - theoretically speaking - quite huge, but we have to focus our attention towards existing practices within social media. Researchers Boyd and Ellison stress the following conclusions: "What makes social network sites unique is not that they allow individuals to meet strangers, but rather that they enable users to articulate and make visible their social networks. This can result in connections between individuals that would not otherwise be made, but that is often not the goal, and these meetings are frequently between 'latent ties' who share some offline connection. On many of the large SNSs, participants are not necessarily 'networking' or looking to meet new people; instead, they are primarily communicating with people who are already a part of their extended social network" (Boyd, Ellison 2008, 211). The distinctive feature of social media is that they are ego centric not topic centric. "Although we speak of 'social media', many contemporary social media platforms logic is quite individualistic. They are called Facebook, YouTube or MySpace and not WeBook, OurTube or OurSpace because they are all about the self-presentation of the individual (networked) self” (Fuchs 2017, 36).

In the 90s of the previous century, the situation was different; individuals in online forums and chat groups usually started online conversations with strangers around some common topic or interest. The

\footnotetext{
${ }^{1}$ There are different words describing or referring to the same thing. A social networking service (also social networking site, SNS or social media) is a web application that people use to build social networks or social relations with other people who share similar personal or career interests, activities, backgrounds or real-life connections.(https://en.wikipedia.org/wiki/Social_networking_service)
} 
topic was a starting point for building relationships and community. Common interests were one of the key arguments why individuals felt they had found their 'own' community, often much more 'authentic' than offline, space-based communities. They found communities which fit perfectly to their lifestyle and way of thinking. Additionally, in the early days of text-based online communication we were faced with a different communication setting, which enabled individuals to completely 'refashion' themselves. The well-known message of that time was: "All they see are your words". Our online discourse was the major channel through which we presented ourselves. Text-based anonymity and the use of nicknames enable the masking of identities and transformations of our presentations within minutes (Poster 1998, 222). Text-based communication enables individuals to present themselves however they want. The discourse was the only identity marker which enabled masquerade, identity switching, pointing to the relevant aspect of the individual. The anonymous computer-mediated environment was a kind of playground for our own exploration.

Such identity experimentation is not popular anymore nowadays. The development of new online platforms, such as social media (Facebook), has brought to us another frame: transparency of the individual. People understand their Facebook profile as their own brand. On social media or social network sites "the focus is not on anonymity but on its opposite - self publication. An SNS affords its users the opportunity not only to publish themselves but also, and crucially, to publish their network" (Lister 2009, 209). Our Facebook identity is not a masquerade; our Facebook identity is sincere, real, transparent. Our social networks are constituted by real offline friends. Fakers are not welcomed. Our identity has to be consistent. But consistency of our online presentations is nevertheless problematic.

\section{Who we are when we are on Facebook? The process of branding of the self}

At first sight, social media are quite different settings from early text-based online communication. In the late $20^{\text {th }}$ century the main goal was to hide, mask, or disguise ourselves. "Disembodiment ${ }^{2}$ (especially anonymity) was the main attraction. Nowadays we are faced with so-called collaborative culture based upon Web 2.0. Accordingly to this new climate we are faced with different kind of activities performed by on-line individuals: to share, to collaborate, to link, to like (as it is in the case of Facebook)" (Praprotnik 2014, 138-139). Within social media we turn our bodies back to face the scene. We usually publish pictures of ourselves, our holiday images and so on. Our Facebook or Instagram publications go hand in hand with our already established offline and online presentations of ourselves. Our image of ourselves, our Facebook identity has constraints again. We have to act and communicate in a way that is consistent with our previous actions in order to stay a 'serious person'. Our Facebook visual and verbal presentations count as an index of our already established Facebook persona.

The critiques of social media optimism stress that "social media foster status-seeking behaviour and thereby promote the infiltration of marketing and advertising techniques into relationships and social behaviour". Alice Marwick, for example, exposes that "social media is predicated on the cultural logic of celebrity, according to which the highest value is given to mediation, visibility, and attention" (Marwick 2013, 14 in Fuchs 2017, 35-36). The existence of certain acts within the Facebook platform (for example, the sign I like) has itself formed an important frame of what is important and what the preferred communication acts within Facebook are. Likes become important, people are focused on collecting these signs. We might claim that 'likes' as communication acts count as preferred responses. Accordingly, people often construct their publications in order to get such response. As Fuchs acknowledged: "The neoliberal logic of competition and individualism is expressed by the fact that on certain social media platforms, one accumulates likes, followers, friends or check-ins, and the more of it one has, the higher one's cultural online capital and social online capital” (Fuchs 2017, 36). We can find similar logic focusing towards improved visibility and constructed 'importance' and impact on

\footnotetext{
2 "Disembodiment signifies that a person's online identity is apparently separate from their physical presence, a condition associated with two features: textuality and anonymity” (Slater 2003, 536).
} 
several platforms, even on those platforms with the motivation to be informative and not just to entertain. But we would like to ask (ourselves) whether the primary goal of social media use is really to entertain, to communicate?

Social media has become a serious business. To what extent are our Facebook presentations a kind of playful intervention in our already constituted identities? When talking about identity we have to bear in mind our audience. "As Goffman originally argued, individuals construct their identities in reaction to their cohorts. To use the language of Web 2.0, individuals construct identities relative to their networks" (Pearson 2009). We are certain that our Facebook performances have to be serious and consistent in order to count as visual and verbal evidences of our Facebook persona. But the very fact that we have to perform consistent identity presentations turns us back to the question of whether our FB identity is a kind of masquerade since we have to present our already established FB image. Is there any space for presentation of other aspects of ourselves? Are we always sincere and 'spontaneous' in our FB performances? Or do we just have to confirm our already established FB persona? By posing these questions we would like to stress that the established use of social media does not give us a lot of space for different self-presentation. The FB profile is a slightly conservative environment limiting the scope of different identity manifestations. Why? We think that a certain level of playfulness would encourage individuals to rethink their already set identities. We are living in an era of self-reflection, in a period which calls for constant exploration of self. Do we really have power only in terms of buying things; are we empowered only as consumers? What kind of power do we have as individuals and as citizens?

Let us go back for some 20 years. In the early days of the internet there were predictions that the virtual environment would engage individuals towards alternative thinking about themselves. The internet offered itself as a counter-balance to the a-priori determinations of an individual. As much as individuals, for example on Internet Relay Chat ${ }^{3}$, freely changed their identities when they were playing different discursive identity games, they soon found out that identity is a construct that was framed for them by others in the 'real' world. In the world of virtual reality, they can construct it themselves, contrary to what happens in the 'real' world (Praprotnik 2014, 139-140). Sherry Turkle in her wellknown book Life on the Screen: Identity in the Age of the Internet saw computer-mediated communication as an emancipator because it allowed people to explore their identity in a socially and physically ‘safe' simulated reality (Turkle, 1995 in Holmes 2011, 107).

What about Facebook identity? Is it serious? Or is it only a well-crafted performance of carefully collected photographs which show our best version of us? Isn't that kind of identity even more virtual? When labelling our Facebook identity as virtual we are pointing to the fact that it is highly intentional and very crafted. Facebook information is to a great extent carefully selected for our Facebook performance. Therefore, every Facebook profile is also a kind of masquerade, a fake. Certainly, every type of our performances is a kind of a masquerade, deliberately crafted for the audience. Even our 'spontaneous' offline performances are to a great extent masquerades, because through socialisation we have learnt scenarios of how to behave properly. So, we are on stage almost all the time. We think that our particular use of social media and constant availability and visibility (always on) weakens any space for different self-reflection. But the choice is, of course, ours.

\footnotetext{
${ }^{3}$ Internet Relay Chat (IRC) is an application layer protocol that facilitates communication in the form of text. After its golden era during the 1990s and early 2000s IRC has seen a significant decline, with users moving to more modern social media platforms.

Available at: https://en.wikipedia.org/wiki/Internet_Relay_Chat
} 


\section{Communication acts within social media}

What kind of communication is typical and welcomed within social media? What kind of identities we are presenting? We think that nobody gives us space and freedom in advance; we have to take it ourselves. Are social media a friendly and encouraging environment for self-reflection? Is networking as an organisational principle successful for the development of more complex, reflective and allencompassing relationships? What are our main communicative intentions when communicating through social media? Do we use social media to develop interpersonal relationships? Are social media more task oriented, topic oriented or more personal/relationship oriented? What kind of relationships are we establishing through social media?

Every type of communication reflects the social roles in which we appear. And vice versa: communication acts conform/constitute social roles; discourse is reflective as well as formative practice. In everyday life we constantly change our communication according to the audience in front of us. The problem is the very environment (social media) which has integrated different social roles into one single profile. As Christian Fuchs stresses: "On social media such as Facebook, we act in various roles, but all off these roles become mapped onto single profile that are observed by different people that are associated with our different social roles. This means that social media are social spaces, in which social roles tend to converge and become integrated in single profiles” (Fuchs 2017, 50). We would like to explicate these quite important aspects by citing a slightly long but very informative and explanatory piece of another of Fuchs' articles: "Social media like Facebook are based on the creation of personal profiles that describe the various roles of a human being's life. In contemporary modern society, different social roles tend to converge in various social spaces. The boundaries between public life and private life as well as the work place and the home have become fuzzy and liquid. As we have seen, Habermas identified systems (the economy, the state) and the lifeworld as central realms of modern society. The lifeworld can be further divided into culture and civil society. We act in different social roles in these spheres: for example, as employees and consumers in the economic systems, as clients and citizens in the state system, as activists in the socio-political and socio-economic spheres, as lovers, consumers or family members in the private sphere, or as fan community members, parishioners, professional association members, etc. in the socio-cultural sphere. A new form of liquid and porous sociality has emerged in which we partly act in different social roles in the same social space. On social media like Facebook, we act in various roles, but all of these roles become mapped onto single profiles that are observed by different people that are associated with our different social roles. This means that social media like Facebook are social spaces in which social roles tend to converge and become integrated in single profiles” (Fuchs 2015, 124-125).

Additionally, social media have quite a strong offline foundation and reflect our already established relationships. The offline and online world are not separated anymore. That is the reason why the 'game' we are playing via social media has become so serious. Our Facebook performances have to count as serious and interesting. Nevertheless, do we really want to be always serious and interesting? Or to put the problem another way: is it better to be 'interesting' and in 'good shape' or is it better to be 'whole'? What would you prefer? We are going to look at our online practices a little more closely and rethink networking as a dominant mechanism.

\section{Networking or communication: what would you prefer?}

Our permanent availability and visibility results in a certain kind of connections: we have connections with lots of people within social media, but are we really connected to people? Quite the contrary; maybe we have an even smaller number of deep relationships than ever before and we would like to present some explanations. 
As a start, it is useful to stress the distinction between network and networking. In their article Danah M. Boyd and Nicole B. Ellison made a very clear distinction:

"Networking emphasizes relationship initiation, often between strangers. While networking is possible on these sites, it is not the primary practice on many of them, nor is it what differentiates them from other forms of computer-mediated communication (CMC)" (Boyd, Ellison 2008, 211). As Boyd and Ellison stress: "While their key technological features are fairly consistent, the cultures that emerge around SNSs are varied. Most sites support the maintenance of pre-existing social networks, but others help strangers connect based on shared interests, political views, or activities" (Boyd, Ellison 2008, 210). With social media, lots of people got a very useful type of technology which enabled them to be in touch with their friends, classmates, and family members. But what about beyond that already known network? What are the possible problems when we build our everyday life within the same 'old' network?

The cultural logic of visibility and prolongation of offline networks constitutes communication practices within social media to a great extent. Kate Hopkins states that "this type of almost constant communication between users has never been available to society in another way, and if anything intensifies the requirement for relationship building - we are now in each other's spaces all the time" (Hopkins 2014, 4). "Social media provide outlets for individuals who already have connections external to these media. They become users of this media to continue physical assemblies in an online environment, but in ways that seek to maximize attention. Where offline relationships simply migrate to social media, recent studies show that the primary forms of use and gratifications are maintaining a connection and an online presence, rather than exchanging information that is of any kind of educational, political or economic value" (Holmes 2011, 105-106). This need for permanent visibility is a kind of reflection of a modern understanding of media. Let's quote Nick Couldry: “... once the media (in any form) presents itself as the centre of society and we organise our lives and orient our daily rituals and practice towards it, we run the risk of falling prey to 'the myth of the mediated centre" (Couldry 2003, 47 in Curran et al, 2012, 125). "Media rituals not only stress the significance of media but also allude to the importance of being 'in the media' and of being able to communicate your message to others whether this be for financial, political or social gain. The more powerful and influential you are, the better placed you are to get your message across. The internet and social networking push this argument one step further. The millions of people who use social networking sites inhabit a mediated world that offers the possibility of more control than mainstream media, is mobile, interactive and holds endless creative potential, but is nonetheless mythic. The claimed ubiquity of the internet and social media stresses the significance of always being tuned in and online. The seductive power of this mythic centre circulates around social life and serves to obscure the reproduction of the dominant values of neoliberal society” (Curran, Fenton, Freedman 2012, 125).

\section{Maintaining a connection: a phatic communion?}

Within social media the practice of linking and networking as a means of establishing visibility is of special importance. The primary goal is often not the dissemination of information but rather preserving connections. In a network society, connections are a kind of capital. Vincent Miller similarly summarises key notions about social media as follows: "The point of the social networking profile is blatantly to establish (and demonstrate) linkages and connections, rather than dialogic communications. Thus, what is seen here is a shift in emphasis from blogging technology which encouraged the creation of substantive text along with networking, to social networking profiles which emphasize networking over substantive text and dialogue of the blog further into a realm of new media culture which I refer to as the phatic” (Miller 2008, 393).

The term phatic was firstly used by anthropologist Bronislaw Malinowski (Malinowski 1999, 303-304) to describe a communicative gesture that does not inform or exchange any meaningful information or 
facts about the world. Its purpose is a social one, to express sociability and maintain connections or bonds. By phatic communication we are keeping connections 'open'.

Social media are tools to extend our already established social networks. As David Holmes states in his article "What is 'social' about social media?": "social media are entirely modelled on the analogue of face-to-face communication, and the microsociology of everyday life. [ ] ... social media is overwhelmingly used to extend offline relationships rather than establish new ones" (Holmes 2011, 108). "Thus the most attractive forms of online connectivity are based on avoiding accidental contact with strangers, and social bonding based upon the electronic maintenance of a closed system of personal networks. [ ]...such bonding is very low in content and information and consists in an electronic version of what might otherwise be called 'small talk'” (Holmes 2011, 105). Vincent Miller describes such type of communication in a similar manner: "One can see this type of communicative practice as largely motivated less by having something in particular to say (i.e. communicating some kind of information), as it is by the obligation or encouragement to say 'something' to maintain connections or audiences, to let one's network know that one is still 'there'” (Miller 2008, 393).

We are witnessing the same transformation from communication towards mere connection when analysing the use of smartphones. Texting a message is a very popular practice: to connect, just to 'say' I am still here. It is obvious that what fascinates users of social media and users of smartphones is the very act of connecting, being connected. But that kind of communication is difficult to be about selfreflection and exploration of me and you and our relationship. The younger generations prefer sending an SMS instead of having a telephone conversation. Typing a message (texting) is not as stressful as conversation. What is the potential result of being constantly connected to other people? We are in a position where we could to lose the ability to be in solitude and to feel good in solitude. We could lose the ability to learn to live at least from time to time in solitude: "These days, social media continually asks us what's 'on our mind', but we have little motivation to say something truly self-reflective. Selfreflection in conversation requires trust. It's hard to do anything with 3,000 Facebook friends except connect" (Turkle 2012). As Sherry Turkle exposed in the interview: "We expect more from technology and less from one another and seem increasingly drawn to technologies that provide the illusion of companionship without the demands of relationship"(Turkle, 2012). "We think constant connection will make us feel less lonely. The opposite is true. If we are unable to be alone, we are far more likely to be lonely. If we don't teach our children to be alone, they will know only how to be lonely” (Turkle, 2012).

Permanent connectivity and branding of the self is also a particular burden for developing critical understanding of the self. To a great extent our previous Facebook publications dictate/frame our current choices of what kind of information we are going to publish. In that sense, Facebook identity is not freefloating, it is not a subject of experimentation. Within social media we construct a single profile with permanent information: "[Teens] felt that on Facebook their life story followed them through their lives in a way that their older brothers and sisters were allowed to start fresh when they moved from elementary school to junior high, from junior high to high school, and then crucially from high school to college. And one said to me, 'My god, it used to be you that when you went to college, you got a chance to start fresh, to be a new person. I bet that was great.' And I think that this sense of the Facebook identity as something that follows you all your life is something that many adolescents feel is a burden." (Turkle 2012). Through constant use of social media there is a danger for individuals 'to learn' and to acknowledge that what really counts and has real weight is our profile, our brand. Without a doubt, our use of technologies constructs different orientations toward ourselves. What counts, what is important? Through social media manifestations and interactions, the younger generation get quite different 'instructions for life'. 


\section{The power to choose as a potential and an obstacle}

Within social media we can also detect a lack of variety. We would like to quote just one example: "What is equally remarkable among different countries, is how much homogeneity there is in this diversity. Social media present an idealised self and an idealised or desired lifestyle everywhere" (Schroeder 2016, 5638). We can say that cultural expectations are reinforced here, because social media - among other things — enable community (or network) building on the basis of the quite the same 'taste'. Social media are effective tools for prolongation of imagined communities and a place for gathering and circulation of the individuals with the same political or cultural motivation. The question is whether social media enable an environment for better information exchange. Do social media encourage dissemination of information about important political, ecological, and educational problems? Again, we must stress that technology is not able to change us, technology is not able to save us-from ourselves. Networking could be an ideal organisational principle for networking of information and ideas; instead, we are faced with networking of individuals. What is the consequence of having the power to choose what kind of information best suits my own interests?

Cass Sunstein in his influential book made an introduction referring to Nicholas Negroponte who "prophesied the emergence of 'the Daily Me'. With the Daily Me, he suggested, you would not rely on the local newspaper to curate what you saw, and you could bypass the television networks. Instead, you could design a communication package just for you, with each component fully chosen in advance [...] What matters is that with the Daily Me, everyone could enjoy an architecture of control. Each of us would be fully in charge of what we see and hear” (Sunstein 2017, 1).

Is that kind of power or 'architecture of control' creative and refreshing in advance? We think the power to choose means also the power not to choose. If we are in full command to choose what we read, listen to and hear, we are also in a position to avoid important information needed for full participation in everyday life. We already know the concept of homophily: a strong tendency to connect and bond with people who are like us. Within social media platforms these processes can be even intensified. As Sunstein acknowledges: “... it is much too simple to say that any system of communication is desirable if and because it allows individuals to see and hear what they choose. Increased options are certainly good, and the rise of countless niches has many advantages. But unanticipated, unchosen exposures and shared experiences are important too" (Sunstein 2017, 8). As Sunstein continues: "people should be free to choose. But freedom requires far more than that. It requires certain background conditions, enabling people to expand their own horizons and to learn what is true. [...] Real world interactions often force us to deal with diversity, whereas the virtual world may be more homogenous, not in demographic terms, but in terms of interest and outlook" (Putnam 2000, 178, in Sunstein 2017, 13). From the democratic point of view, the freedom to choose is little problematic: "a system of free expression should not be seen solely in terms of consumers and consumption at all. In a free republic, such a system is designed to maintain the conditions for democratic self-government - to serve citizens, not only consumers" (Sunstein 2017, 234). "A society with general-interest intermediaries, like a society with a robust set of public forums, promotes a shared set of experiences at the same time that it exposes countless people to information and opinions that they would not have sought out in advance” (Sunstein 2017, 234). "Indeed, the Internet creates a large risk of group polarization, simply because it makes it so easy for like-minded people to speak with one another - and ultimately move toward extreme and sometimes even violent positions. All too often, those most in need of hearing something other than echoes of their own voices are the least likely to seek out alternative views. The result can be cybercascades of a highly undesirable sort, as false information spreads to thousands or even millions” (Sunstein 2017, 236-237). 


\section{Conclusion}

Our intention is not to claim that we all have the same information needs and that government or some other external force dictates to people what kind of information is important for their well-being. Nevertheless, we want to stress that freedom to choose and power to choose function as a double-edged sword. Power to choose is not the sole solution for developing a well-informed citizen. We would like to stress that it is of vital importance to be aware that we as individuals are not only consumers with special, often personalised interests, motivations and needs that have to be accomplished/fulfilled. We are at the same time also citizens. And citizens usually have slightly broader interests and motivations. A citizen is not driven only in terms of consumption. A citizen's motivations are more holistic, his motivations are not based only in terms of 'my needs', but in terms of 'our needs' as a society. In a modern media-saturated world with vast opportunities, it is—paradoxically—of special importance to be well-equipped with knowledge in order to fully understand the complexity of everyday life. Freedom demands responsibility and the ability to contextualise information. Nowadays, the responsibility of the individual for well-being is not smaller. The responsibility is bigger. We need media as well as all other literacies in order to fully command our everyday life.

It is important to be informed with all different kinds of information in order to get a picture of the world and to become competent and well-informed citizens. But the problem is not only the exposure to different information, the problem is much more complex. Lots of people believe that social media platforms will deliver them all the information needed to be a well - informed citizen. Jane Buckingham, the founder of the Intelligence Group, a market research company, said that the "social media generation' was comfortable being in constant communication with others, so recommendations from friends or text messages from a campaign — information that is shared, but not sought — were perceived as 'natural'" (Stelter 2008). Namely, it is quite common that people assume something as follows: "If the news is that important it will find me". Is that assumption correct? We strongly disagree. In the period of traditional media corporations, we were 'forced' to consume news that was selected by media corporations. Nowadays, lots of people believe they will get important news from their Facebook friends. Zúñiga, Weeks and Ardèvol Abreu stress that the news finds me perception "captures people's perceptions that news will simply 'find' them without seeking it. Importantly, the news finds me perception does not reflect ambivalence toward using news to stay informed-it is not that those who hold this perception are necessarily uninterested in what is happening in the world-but rather believe that they do not need to actively seek news because their other media behaviors and social network provide all the news they require to stay informed []Citizens today arguably have more opportunities to encounter news and political information than ever before. At first glance, the widespread availability of news might be considered ideal for producing better informed citizens, especially given that both the volume and breadth of news in the media environment promote learning about politics. While the abundance of media options may provide citizens more opportunities to learn from the news, some scholars argue that this high choice media environment may instead have negative democratic consequences by enhancing political knowledge gaps based on content preferences, interest, and usage patterns” (Zúñiga, Weeks and Ardèvol Abreu 2017, 107).

Our media environment is certainly very diverse. We are well equipped with smartphones and other devices which constantly deliver information to us. But for fully competent citizens it is important that we know what kind of information is relevant for us. 


\section{References}

Barber, Benjamin R. 2002. “The Ambiguous Effects Of Digital Technology On Democracy In A Globalizing World". In Beitrag zum Kongress "Gut zu Wissen", Heinrich-BöllStiftung.http://www.wissensgesellschaft.org/themen/demokratie/democratic.html

Boyd, Dana M., Ellison, Nicole B. 2008. "Social network sites: Definition, history, and scholarship.” Journal of Computer-Mediated Communication 13, no.1: 210-230.

https://onlinelibrary.wiley.com/doi/epdf/10.1111/j.1083-6101.2007.00393.x

Castells, Manuel. 2014. “The Impact of the Internet on Society: A Global Perspective.” In Change: 19 Key Essays on How the Internet Is Changing Our Lives. OpenMind. https://www.bbvaopenmind.com/en/articles/the-impact-of-the-internet-on-society-a-globalperspective/

Couldry, Nick. 2003. Media Rituals: A Critical Approach. London: Routledge.

Curran, James, Fenton, Natalie, Freedman, Des. 2012. Misunderstanding the Internet. London and New York: $\quad$ Routledge. $\quad$ https://courses.helsinki.fi/sites/default/files/coursematerial/4511752/CURRAN\%20ET\%20AL_Misunderstanding\%20the\%20internet.pdf

DiMaggio, Paul. 2014. "The Internet's Influence on the Production and Consumption of Culture: Creative Destruction and New Opportunities.” In Change: 19 Key Essays on How the Internet Is Changing Our Lives. OpenMind. https://www.bbvaopenmind.com/en/article/the-internets-influence-on-the-production-andconsumption-of-culture-creative-destruction-and-new-opportunities/?fullscreen=true

Fuchs, Christian. 2015. "Power in the Age of Social Media." Heathwood Journal of Critical Theory1, no. 1 (September):1-29. https://westminsterresearch.westminster.ac.uk/item/99573/power-in-theage-of-social-media

Fuchs, Christian, Trottier, Daniel. 2015. "Towards a theoretical model of social media surveillance in contemporary society.” Communications 40, no. 1: 113-135. DOI: https://doi.org/10.1515/commun-2014-0029.

Fuchs, Christian. 2017. Social media: A critical introduction. Los Angeles, London, New York: SAGE Publications. http://fuchs.uti.at/books/2nd-edition-social-media-a-critical-introduction/

Gil de Zúñiga, Homero, Weeks, Brian, Ardèvol-Abreu, Alberto. 2017. "Effects of the News-Finds-Me Perception in Communication: Social Media Use Implications for News Seeking and Learning About Politics.” Journal of Computer-Mediated Communication 22, no. 3: 105-123. https://onlinelibrary.wiley.com/doi/10.1111/jcc4.12185

Hepp, Andreas, Hasebrink, Uwe. 2018. "Researching Transforming Communications in Times of Deep Mediatization: A Figurational Approach.” In Communicative Figurations; Transforming Communications in Times of Deep Mediatization, edited by Andreas Hepp, Andreas Breiter, Uwe Hasebrink, 15-48. Transforming Communications - Studies in Cross-Media Research. Palgrave Macmillan, Springer. (e-book). https://link.springer.com/content/pdf/10.1007\%2F978-3-31965584-0.pdf

Holmes, David. 2011. "What is 'social' about social media?” Communications and Convergence Review 3, no. https://www.kisdi.re.kr/kisdi/fp/kr/board/selectSingleBoard.do?cmd=selectSingleBoard\&boardI d=ENG_RESEARCH_CCR\&seq $=26749 \&$ reStep $=699 \& c t x=$

Hopkins, Kate. 2014. "The phatic nature of the online social sphere: Implications for public relations." Prism 11, no. 2. http://www.prismjournal.org/fileadmin/11_2/Hopkins.pdf

Lister, Martin, Dovey, John, Giddings, Seth, Grant, Iain, Kelly, Kieran. 2009. New Media: a critical introduction. Second edition. London and New York: Routledge, Taylor \& Francis Group.

Malinowski, Bronislaw. 1999. “On Phatic Communion.” In The Discourse Reader, edited by Adam Jaworski and Nikolas Coupland, 302-305. London and New York: Routledge.

Marwick, Alice E. 2013. Status Update: Celebrity, Publicity, and Branding in the Social Media Age. New Haven: Yale University Press. 


\section{(Mic $_{2019}$ \\ Management International Conference \\ Opatija, Croatia • 29 May-1 June 2019}

Miller, Vincent. 2008. "New Media, Networking and Phatic Culture.” Convergence: The International Journal of Research into New Media Technologies 14, no. 4: 387-400. https://journals.sagepub.com/doi/pdf/10.1177/1354856508094659

Pearson, Erika. 2009. "All the World Wide Web's a stage: The performance of identity in online social networks." First Monday; Peer-revieved journal on the Internet 14, no. 3. http://firstmonday.org/ojs/index.php/fm/article/view/2162/2127

Poster, Mark. 1998. "Virtual Ethnicity: Tribal Identity in an Age of Global Communications." In Cybersociety 2.0; Revisiting Computer-Mediated Communication and Community, edited by Steven G. Jones, 184-211. Thousand Oaks, London, New Delhi: New Media Cultures, SAGE Publications.

Praprotnik, Tadej. 2014. “Free-floating identities: social pain or social gain?” Innovative Issues and Approaches in Social Sciences 7, no. 3: 132-147. http://www.iiass.com/pdf/IIASS-2014-no3art07.pdf DOI: http://dx.doi.org/10.12959/issn.1855-0541.IIASS-2014-no3-art07.

Putnam, Robert D. 2000. Bowling Alone: the collapse and revival of American community. New York: Simon \& Schuster.

Schroeder, Ralph 2016. "The Globalization of On-Screeen Sociability: Social Media and Tethered Togetherness." International Journal of Communication 10: 5626-5643. http://ijoc.org/index.php/ijoc/article/viewFile/5729/1846

Slater, Don. 2003. “Social Relationships and Identity Online and Offline.” In The Handbook of New Media, edited by Leah Lievrouw and Sonia Livingstone, 533-546. London, Thousand Oaks, New Delhi: SAGE Publications.

Stelter, Brian. 2008. "Finding Political News Online, the Young Pass It On.” New York Times, March 27 2008. https://www.nytimes.com/2008/03/27/us/politics/27voters.html

Sunstein Cass R. 2017. \#Republic: Divided Democracy in the Age of Social Media. Princeton and Oxford: Princeton University Press.

Turkle, Sherry. 1995. Life on the screen: Identity in the age of the Internet. New York: Simon \& Schuster.

Turkle, Sherry. 2012. “In Constant Digital Contact, We Feel Alone Together.”; Interview with Sherry Turkle. Fresh Air, NPR, October 17, 2012. http://www.npr.org/2012/10/18/163098594/inconstant-digital-contact-we-feel-alone-together

Wikipedia, $2019 . \quad$ "Social networking service." https://en.wikipedia.org/wiki/Social_networking_service

Wikipedia, 2019. “Internet Relay Chat.” https://en.wikipedia.org/wiki/Internet_Relay_Chat 